\title{
Karakteristik Program dan Kelompok serta Kendala Pelaksanaan Program Simantri di Kabupaten Badung
}

\author{
I PUTU PURNA JAYA, I DEWA PUTU OKA SUARDI, \\ I KETUT BUDI SUSRUSA
}

\author{
Program Studi Agribisnis, Fakultas Pertanian, Universitas Udayana \\ Jalan P.B. Sudirman Denpasar 80232 \\ Email: purnajaya12@yahoo.com \\ okasuardi@unud.ac.id
}

\section{Abstract \\ Characteristics of Program and Group and Implementation Obstacle Simantri Program in Badung regency}

Integrated Farming System or Simantri is a breakthrough effort to accelerate the adoption of agricultural technology, Simantri Program development goal is to support integrated diversification of farming to local potentials, to increase income to alleviate poverty, to integrate crop and livestock farming, and to pioneer the development of integrated agriculture in a sustainable manner. The purpose of this research is to investigate the Characteristic of Program and Characteristic of Group, and Constraints of Simantri Program Implementation in the Badung Regency.. The results showed that the Characteristics of Simantri Program is quite good with average achievement score of 3.8, Characteristics of Simantri group is good with average achievement score of 4.1, constraints faced in the characteristics of the program i.e. optimal cattle maintenance management, cattle maintenance, inadequate cage quality and many are not functioning properly, cow urine channel and bio-urine processing tools are easily damaged, bio-gas was also easily damaged, and the location of Simantri makes the gas bio channel unable to reach the houses of the Simantri's group, group members rarely processed manure because of their other activities, members were reluctant to maintain and care for planted demonstration plots.

Keywords: program characteristics, group characteristics, constraints on the program implementation, Simantri of the Badung Regency.

\section{Pendahuluan}

\subsection{Latar Belakang}

Indonesia disebut sebagai bangsa yang agraris, namun seiring berjalannya waktu mulai kehilangan julukan itu. Hal ini dikarenakan rendahnya produktivitas tanaman pangan seperti, penerapan teknologi budidaya di lapangan yang masih rendah, tingkat 
kesuburan lahan yang terus menurun dan eksplorasi potensi genetik tanaman yang masih belum optimal (Guedev S Kush, 2002). Provinsi Bali memiliki berbagai macam sektor unggulan seperti pariwisata dan pertanian. Sektor pertanian merupakan sektor yang mendapatkan perhatian cukup besar dari pemerintah daerah, dikarenakan peranannya yang sangat penting dalam penyediaaan sumber makanan. Bukti perhatian pemerintah dengan dibuatnya program-program dibidang pertanian. Salah satu program pertanian yang dibuat oleh pemerintah Provinsi Bali (Mangku Pastika) yaitu Simantri (Sistem Pertanian Terintegerasi). Simantri merupakan upaya terobosan dalam mempercepat adopsi teknologi pertanian, tujuan pengembangan Program Simantri adalah untuk mendukung diversifikasi usahatani secara terpadu terhadap potensi lokal, meningkatkan pendapatan untuk mengentaskan kemiskinan, mengintegrasi usahatani tanaman pangan danternak, serta merintis pengembangan pertanian terintegrasi secara berkelanjutan.

Menurut Fouziah (2011), integrasi dilakukan untuk mendaur ulang sumber daya alam secara efisien. Integrasi ternak, ikan dan tanaman terbukti menjadi sistem pertanian yang berkelanjutan.Simantri diharapkan mampu meningkatkan luas tanam, populasi ternak, perikanan dan kualitas hasil agar dapat tersedianya pakan ternak berkualitas, pupuk, pestisida organik serta biogas. Simantri mengintegrasikan kegiatan sektor pertanian dengan sektor pendukungnya sesuai potensi masing-masing wilayah dengan mengoptimalkan pemanfaatan sumberdaya lokal yang ada. Kegiatan integrasi yang dilaksanakan berorientasi pada usaha pertanian tanpa limbah (zero waste) dan menghasilkan $4 \mathrm{~F}$ (food, feed, fertilizer dan fuel). Oleh karena itu menarik untuk dilakukan penelitian mengenai karakteristik program dan karakteristik kelompok serta kendala pelaksanaan program Simantri di Kabupaten Badung.

\subsection{Tujuan Penelitian}

Sejalan dengan permasalahan yang telah dirumuskan, maka tujuan dari penelitian ini untuk: (1) untuk mengetahui karakteristik program Simantri di Kabupaten Badung, (2) untuk mengetahui karakteristik kelompok Simantri di Kabupaten Badung, (3) untuk mengetahui kendala yang dihadapi dalam pelaksanaan program di Kabupaten Badung.

\section{Metode Penelitian}

\subsection{Lokasi dan Waktu Penelitian}

Penelitian ini dilakukan di Kabupaten Badung khususnya di tiga Kecamatan yaitu Kecamatan Mengwi, Kecamatan Abiansemal, dan Kecamatan Petang, dari ketiga kecamatan ini dipilih tiga Simantri yaitu Simantri 243, Desa Jagapati, Kecamatan Abiansemal, Kabupaten Badung, Simantri 007, Desa Pangsan Kecamatan Petang Kabupaten Badung, dan Simantri 525, Desa Sembung, Kecamatan Mengwi, Kabupaten Badung. Pemilihan lokasi penelitian ini di lakukan dengan metode purporsive (sengaja) dengan pertimbangan bahwa Simantri tersebut merupakan Simantri yang mengalami 
kendala yang menghambat kemajuan program Simantri. Penelitian berlangsung dari bulan April 2016 s.d. bulan Desember 2017.

\subsection{Penentuan Populasi dan Responden}

Menurut Effendi dan Singarimbun (1998). Populasi adalah keseluruhan dari unit analisis yang ciri-cirinya akan diduga. Populasi penelitian ini meliputi seluruh anggota dari tiga kelompok Simantri yang berjumlah 60 orang. Metode sampling yang digunakan adalah metode quota sampling. Menurut Sugiyono (2011) menyatakan bahwa sampling kuota adalah teknik untuk menentukan sampel dari populasi yang mempunyai ciri-ciri tertentu sampai jumlah (kuota) yang diinginkan. Penentuan responden menggunakan teknik purposive random sampling. Menurut Riduwan (2010), purposive random sampling (sampling pertimbangan) ialah teknik sampling yang digunakan peneliti jika peneliti mempunyai pertimbangan-pertimbangan tertentu dalam pertimbangan sampelnya untuk tujuan tertentu.

\subsection{Data penelitian}

Data Penelitian yang berupa jenis data, sumber data, teknik pengumpulan data, instrumen penelitian dalam karakteristik program dan karakteristik kelompok, serta kendala pelaksanaan Program Simantri di Kabupaten Badung akan di jelaskan sebagai berikut.

\subsubsection{Jenis data}

Jenis data dalam penelitian ini yaitu data kualitatif dan data kuantitatif. Menurut Muhadjir (1996) data kualitatif yaitu data yang disajikan dalam bentuk kata verbal bukan dalam bentuk angka. Menurut Sugiyono (2015) data kuantitatif adalah data yang diperoleh dalam bentuk angka-angka yang dapat dihitung, berkaitan dengan masalah yang diteliti.

\subsubsection{Sumber data}

Sumber data penelitian ini yaitu data primer dan data sekunder. dengan penjelasan sebagai berikut ini. Data Primer. Menurut Narimawati (2008), Data primer ialah data yang berasal dari sumber asli atau pertama, sedangkan data Sekunder menurtut Sekaran (2011), merupakan sumber data yang mengacu pada informasi yang dikumpulkan dari sumber yang telah ada. Sumber data sekunder adalah catatan atau dokumentasi perusahaan, publikasi pemerintah, analisis industri oleh media, situs Web, internet dan lain-lain. 


\subsection{Variabel, dan Pengukuran}

Variable karakteristik program dan karakteristik kelompok serta kendala pelaksanaan Program Simantri di Kabupaten Badung, digunakan untuk mengetahui karakteristik program, karakteristik kelompok, dan kendala pelaksanaan Program Simantri di Kabupaten Badung. Pengukuran dilakukan dengan metode skoring 1 s.d 5.

\subsection{Metode Analisis Data}

Menurut Sugiyono (2010) analisis data merupakan proses mencari dan menyusun secara sistematis data yang diperoleh dari hasil wawancara, catatan lapangan, dan dokumentasi. Analisis data dilakukan secara deskriptif kualitatif. Analisis ini juga dibantu dengan menggunanakan skor yaitu skala dari 1,2,3,4,5 yang menyatakan tentang karakteristik program, kelompok, dan kendala pengembangan Simantri di Kabupaten Badung dapat di lihat pada Tabel 1.

Tabel 1.

Karakteristik Program dan Kelompok serta Kendala Pelaksanaan Program Simantri di Kabupaten Badung

\begin{tabular}{ccc}
\hline No & Pencapain skor & Kategori \\
\hline 1. & $4,2-5$ & Sangat baik \\
2. & $3,4-4,2$ & Baik \\
3. & $2,6-3,4$ & Cukup baik \\
4. & $1,8-2,6$ & Kurang baik \\
5. & $1-1,8$ & Sangat kurang baik \\
\hline
\end{tabular}

\section{Hasil dan Pembahasan}

\subsection{Karakteristik Program Simantri}

Karakteristik Program Simantri tergolong baik dengan rata-rata Skor 3,8 lebih jelas pencapaian skor Karakteristik Program Simantri dapat dilihat pada Tabel 2.

Tabel 2.

Distribusi Responden Berdasarkan Karakteristik Program Simantri

\begin{tabular}{cccc}
\hline & Kategori & \multicolumn{2}{c}{ Jumlah } \\
\cline { 2 - 4 } Pencapaian Skor & & Oran & \multirow{2}{*}{$\mathrm{g}$} \\
\hline $4,2-5$ & Sangat baik & - & - \\
$3,4-4,2$ & Baik & 29 & 96,7 \\
$2,6-3,4$ & Cukup baik & 1 & 3,3 \\
$1,8-2,6$ & Kurang baik & - & - \\
$1-1,8$ & Sangat kurang baik & - & - \\
\hline
\end{tabular}


Tabel 2 menyatakan sebanyak 96,7\% responden menyatakan Karakteristik Program Simantri baik, 3,3\% menyatakan cukup baik.ini dikarenakan anggota simantri merasa terbantu oleh program Simantri yang diberikan oleh Pemerintah Provinsi Bali, adapun beberapa indikator dalam karakteristik Program Simantri yang berupa Keuntungan Program, Kesesuaian Program, dapat dilaksanakan, dan adanya pendampingan secara lebih jelas dapat dilihat pada Tabel 3.

Tabel 3.

Distribusi Responden Berdasarkan Indikator Kararakteristik Program Simantri

\begin{tabular}{rlcl}
\hline \multirow{2}{*}{ No } & \multicolumn{1}{c}{ Indikator } & \multicolumn{2}{c}{ Rata-Rata } \\
Karakteristik Program Simantri & Pencapaian Skor & Kategori \\
\hline 1 & Keuntungan Program & 3,6 & Menguntungkan \\
2 & Kesesuaian Program & 3,8 & Sesuai \\
3 & Dapat Dilaksanakan & 3,6 & Baik \\
4 & Adanya Pendampingan & 4,1 & Baik \\
\hline Karakteristik Program Simantri & 3,8 & Baik \\
\hline
\end{tabular}

Table 3 menunjukan pencapaian skor rata-rata responden karakteristik Program Simantri di Kabupaten Badung pada indikator keuntungan program sebesar 3,6 dengan kategori menguntungkan kategori menguntungkan kategori menguntungkan pada keuntungan program ini terjadi karena program simantri ini merupakan program yang diberikan pemerintah kepada anggota secara cuma-cuma. Setiap bantuan yang diberikan semua murni milik anggota simantri karena pemerintah tidak meminta pengembalian dalam bentuk apapun.

\subsection{Karakteristik Kelompok Simantri}

Karakteristik kelompok Simantri tergolong baik dengan rata-rata Skor 4,1 lebih jelas pencapaian skor Karakteristik Program Simantri dapat dilihat pada Tabel 4. 
Tabel 4.

Distribusi Responden Berdasarkan Indikator Karakteristik

Kelompok Simantri tahun 2017

\begin{tabular}{clcc}
\hline $\mathrm{N}$ & \multicolumn{1}{c}{ Indikator } & $\begin{array}{c}\text { Rata-rata } \\
\text { Pencapaian skor }\end{array}$ & Kategori \\
\hline 1 & \multicolumn{1}{c}{ Karakteristik program Simantri } & 4,0 & Baik \\
2 & Interaksi dan interelasi sesama anggota & 4,0 & Baik \\
3 & Struktur dan pembagian tugas & 4,25 & Baik \\
4 & Kaidah dan norma yang dispakati & 3,77 & Baik \\
& Bersama & & \\
5 & Keinginan dan tujuan bersama & 4,35 & Sangat Baik \\
\hline Karakteristik program Simantri & 4,1 & Baik \\
\hline
\end{tabular}

Indikator ikatan yang nyata mendapatkan rata-rata skor sebesar 4,0 yang termasuk dalam kategori baik. Rata-rata skor baik ini didukung dengan keseriusan petani dalam mengikuti program Simantri dan pembagian tugas yang baik untuk semua anggota. Ini dikarenakan jika dijalankan dengan serius tentu Simantri ini dapat memberikan banyak keuntungan bagi anggotanya dan jika pembagian tugasnya juga baik maka program Simantri mampu berjalan dengan baik, program Simantri merupakan program yang terintegrasi dan semua limbah yang dihasilkan Simantri dapat diolah menjadi bahanbahan yang berguna bagi petani sperti urin sapi yang bisa digunakan sebagai pestisida alami, dan kotoran sapi yang bisa digunakan sebagai pupuk organik.

\subsection{Kendala Program Simantri}

Program pemeliharaan sapi mengalami beberapa kendala di antranya dalam program pemeliharaan sapi, pembuatan bio urin, pembuatan bio gas, pembuatan pupuk organik, dan penanaman demplot.adapun kendala-kendala tersebut adalah sebagai berikut.

1. Program pemeliharaan sapi terkendala oleh manajemen pengelolaan sapi yang belum optimal, ada juga masalah teknis yang menyebabkan pemeliharaan sapi menjadi tidak optimal misalnya kandang yang rusak.

2. Program pengolahan bio urin murni terkendala oleh masalah teknis masalah teknis tersebut diantaranya masalah saluran kencing sapi yang rusak dan alat pengolahan bio urin yang cepat rusak. 
3. Program pengolahan biogas juga mengalami masalah teknis diantaranya alat yang rusak dan lokasi pembuatan bio gas yang jauh dari pemukiman sehingga tidak bisa menjangkau pemukiman anggota Simantri.

4. Program pembuatan pupuk organik mengalami kendala diantaranya anggota kelompok yang enggan untuk mengolah pupuk, dan beberapa masalah teknis berupa kesibukan masing-masing anggota sehingga tidak mampu mengolah pupuk, lokasi Simantri yang tidak mendapat akses jalan juga menjadi kendala dalam pendistribusian pupuk.

5. Program penanaman Demplot terkendala kemauan anggota untuk memelihara dan merawat tanaman yang sudah ditanam dan ada beberapa masalah teknis dalam penanaman dan pemeliharaan tanaman diantaranya masih kurang beragamnya jenis tanaman yang ditanam dan lain sebagainya

\subsection{Kendala kelompok Simantri}

Dalam kelompok Simantri kendala yang dihadapi adapun kendala-kendala tersebut adalah sebagi berikut.

1. Petani mengeluhkan minimya generasi penerus yang akan menggantikan mereka ketika sudah tidak mampu lagi mengurus sapi yang ada di Simantri

2. Program Simantri tidak terlaksana karena anggota mempunyai kesibukan lain selain mengelola Simantrinya.

3. Ada beberapa anggota Simantri yang sudah mengundurkan diri maupun yang sudah meninggal.

4. Rapat yang seharusnya dilakukan setiap bulannya terkendala oleh adanya kegiatan lain baik itu kegiatan sosial di masyarakat seperti ngayah banjar maupun bekerja.

Banyak anggota kelompok yang hanya menjadikan program Simantri sebagai pekerjaan sampingan sehingga kurang optimal dalam melaksanakan program. 


\section{Simpulan dan Saran}

\subsection{Simpulan}

Berdasarkan hasil dan pembahasan yang telah dilakukan, maka dapat ditarik simpulan sebagai berikut.

1. Karakteristik program Simantri tergolong baik dengan pencapaian rata-rata Skor sebesar 3,8.

2. Karakteristik kelompok Simantri tergolong baik dengan pencapaian rata-rata Skor 4,1.

3. Kendala dalam pelaksanaan Program Simantri berdasarkan kerakteristik program meliputi : (1) manajemen pemeliharaan sapi kurang optimal, menyangkut teknis pemeliharaan sapi, kualitas kandang kurang memadai dan banyak yang tidak berfungsi dengan baik; (2) saluran urin sapi dan alat pengolahan bio urin cepat rusak; (3) instalasi bio gas cepat rusak, dan sarulan bio gas tidak mampu menjangkau pemukiman anggota kelompok Simantri karena lokasi unit Simantri jauh; (4) karena memiliki kesibukan lain anggota kelompok jarang mengolah pupuk, dan (5) anggota kelompok enggan untuk memelihara dan merawat tanaman demplot yang sudah ditanam. Kendala pelaksanaan Program Simantri berdasarkan karakteristik kelompok meliputi: (1) Kurangnya generasi penerus sebagai anggota kelompok yang akan menggantikan mereka ketika sudah tidak mampu lagi mengurus sapi yang ada di Simantri, dan (2) Banyak anggota kelompok yang hanya menjadikan program Simantri sebagai pekerjaan sampingan karena mereka memiliki pekerjaan pokok lain sehingga pelaksanaan aktivitas dalam Simantri kurang optimal.

\subsection{Saran}

Saran dari penelitian Simantri karakteristik program dan kelompok serta kendala pelaksanaan Program di Kabupaten Badung sebagai berikut.

1. Pelaksanaan Program Simantri akan lebih baik jika anggota simantri mau bersungguh-sungguh dalam melaksanakan setiap program yang ada di Simantri terutama dalam terutama program pengolahan pupuk organik, pembuatan bio gas, pembuatan bio urin, dan demplot. Beberapa kendala yang terjadi dalam program simantri dapat diatasi dengan keseriusan anggota simantri dalam menjalankan setiap programnya mulai dari pemeliharaan sapi tetapi jangan sampai anggota hanya mengutamakan pemeliharaan sapi tetapi tidak memperhatikan program lainyak karena setiap program tersebut akan memberikan keuntungan bagi anggota Simantri, dan jika memungkinkan dalam menjalankan program Simantri jangan jadikan Simantri hanya sebagai pekerjaan sampingan karena jika dijalankan dengan serius Simantri ini bisa mensejahterakan semua anggota Simantri karena semua program Simantri merupakan program yang bertujuan untuk mensejahterakan anggotanya. Akan lebih baik lagi jika pemilihan calon anggota simantri dipilih orang-orang yang benar-benar membutuhkan program 
tersebut sehingga anggota yang menerima bantuan program Simantri ini dapat membantu mensejahterakan anggotanya.

2. Karakteristik kelompok Simantri akan lebih baik jika dalam pemilihan anggota kelompok agar lebih memeperhatikan warga yang kurang mampu dan tidak memiliki pekerjaan lain, sehingga program ini benar-benar mampu membantu warga miskin dan dalam pelaksanaan program ini dapat berjalan dengan baik sesuai tujuan pembuatan program simantri. Rapat bulanan akan lebih baik jika rutin dilakukan karena rapat bulanan ini akan menjadi wadah dalam penyampaian pendapat yang nantinya akan menjadi acuan untuk memajukan kelompok, dan hubungan kekeluargaan dalam Simantri harus dipertahankan agar kekompakan kelompok dalam menjalankan program dapat terjaga. Dalam pemilihan anggota sebaiknya mencari calon anggota yang akan menjadikan simantri sebagai pekerjaan pokok bukan anggota yang hanya sekedar ikut-ikutan ingin memelihara sapi, karena jika ingin Simantri yang dikelola menjadi Simantri yang maju anggota anggota sebaiknya sanggup untuk melaksanakan setiap program yang ada di Simantri tersebut.

\section{Ucapan Terima Kasih}

Penulis menyampaikan terima kasih kepada seluruh anggota Simantri yang telah memberikan data penelitian dan semua pihak yang telah membantu dalam proses penyelesaian penelitian hingga termuat di e-journal.

\section{Daftar Pustaka}

Effendi dan Singarimbun, M. 1998. Metode Penelitian Survei. LP3ES. Jakarta. Fauziah. 2011. Manajemen Sumber Daya Manusia Lanjutan. Madenatera. Medan Gurdev S. khus. 2002. Food Security By Design: Improving The Rice Plant in Partnership With NARS. Makalah disampaikan Pada Seminar IPTEK padi Pekan Padi Nasional di Sukamandi 22 Maret 2002

Muhadjir, Noeng. 1996. Metode Penelitian Kualitatif. Rake Sarasin. Yogyakarta.

Sekaran, Uma. 2011. Research Methods for Business Edisi I and 2. Salemba Empat. Jakarta.

Riduwan. 2010. Metode dan Teknik Menyusun Tesis. Alfab. Bandung.

Sugiyono. 2010. MetodePenelitianPendidikan: PendekatanKuantitatif. Alfabeta. Bandung. 2011. Statistika untuk Penelitian. Alfabeta. Bandung. 2015. Metode Penelitian Kuantitatif, Kualitatif, dan $R \& D$. AFABETA. Bandung.

Narimawati, Umi. 2008. Metodologi Penelitian Kualitatif dan Kuantitatif, Teori dan Aplikasi. Bandung: Agung Media 